\title{
Scientific Progress, Understanding, and Knowledge: Reply to Park
}

\author{
Finnur Dellsén \\ Preprint of discussion note forthcoming in JGPS
}

\section{Introduction}

Dellsén (2017) has recently argued for an understanding-based account of scientific progress, the noetic account, according to which science (or a particular scientific discipline) makes cognitive progress precisely when it increases our understanding of some aspect of the world. Dellsén contrasts this account with Bird's $(2007,2015)$ epistemic account, according to which such progress is made precisely when our knowledge of the world is increased or accumulated. In a recent paper, Park (2017) criticizes various aspects of Dellsén's account and his arguments in favor of the noetic account as against Bird's epistemic account. This paper responds to Park's objections. Since a number of Park's arguments rely on the idea that scientific progress may merely consists in "achieving the means to increase knowledge" (Park 2017: 570), I will start by discussing this "means-end thesis".

\section{Scientific progress vs. promotion of progress}

Bird's original and most frequently used formulation of the epistemic account simply says that an episode in science is progressive precisely when there is more knowledge at the end of the episode than at the beginning (e.g., Bird 2007: 64). In his original paper, Bird also added that certain means to achieving knowledge may also count as progressive (Bird 2007: 83). However, Bird (2008) later responded to an objection made by Rowbottom (2008) by insisting that "we must distinguish what constitutes progress from what promotes it" (Bird 2008: 280). Thus Bird's considered view appears to be that obtaining a mere means to accumulate knowledge - i.e., merely promoting the accumulation of knowledge - is not by itself sufficient for scientific progress. ${ }^{1}$

In spite of this, Park formulates the epistemic account as "the suggestion that scientific progress consists in increasing knowledge or in achieving a means to increase knowledge" (Park 2017: 570 - my emphasis), referring to the second disjunct as "the meansend thesis". The difference between Park and Bird may seem small, but in fact Park immediately infers that even if all past attempts to formulate a true theory within some domain have failed miserably, each attempt would as progressive by his lights provided that these failed attempts later led to the development of a known theory. By contrast, Bird explicitly does not draw this conclusion from his account (see Bird 2007: 73, 79-81). Given

\footnotetext{
${ }^{1}$ I am grateful to an anonymous reviewer for alerting me to the relevance of the exchange between Bird and Rowbottom to this issue.
} 
this difference, I will refer to Park's version of the epistemic account as the extended epistemic account.

There is an immediate difficulty with such an account. As Niiniluoto (2015) emphasizes, the traditional debate about scientific progress concerns the kind of progress that is made in science with regard to our theories' representation of the world - what Niiniluoto calls cognitive progress. There are many other kinds of progress in science, e.g. increased or better funding of science (economic progress), increased skills or expertise among scientists (educational progress), and better methodologies for tackling scientific questions (methodological progress). ${ }^{2}$ Thus, in the relevant sense, an account of scientific progress is really an account of cognitive progress in science. The problem this creates for Park's extended epistemic account is that it seems that most of these other kinds of progress in science would in fact count as (cognitive) scientific progress by the lights of the extended epistemic account. More generally, the underlying problem here is that almost anything can count as progressive on the extended epistemic account, since all that's required is that it is a "means to" acquiring knowledge sometime in the future.

Park appears to be aware of this problem. His suggested solution is to restrict his account to "episodes that involve cognitive changes" (Park 2017: 570). However, it's not hard to see that this modification will not work, ${ }^{3}$ for it has the wrong form: An account of cognitive progress in science is not the same thing as an account of progress over an episode that involves cognitive change. This somewhat subtle difference can be brought out with examples of episodes in which cognitive change does take place, and there is also some kind of scientific progress, but the progress in question is not cognitive. For example, suppose a powerful new funding agency agrees to double the financial resources of an entire scientific discipline, e.g. evolutionary biology, but only on the condition that they all abandon (i.e. cease to accept or believe) the theory of natural selection and instead adopt (i.e. start believing or accepting) a pseudo-scientific theory, e.g. intelligent design. ${ }^{4}$ Clearly, we do not have here a case of scientific progress in the sense relevant to the debate, viz. cognitive scientific progress. On the contrary, the episode would be regressive since the only relevant cognitive change involves abandoning a genuine scientific theory for a pseudoscientific theory. However, this type of episode would count as progressive according to Park's expanded account if, as a matter of fact, the increased funding is a means to later acquire a great deal of knowledge. ${ }^{5}$ This is clearly the wrong result.

For this reason, it's a mistake for epistemicists about scientific progress to formulate the thesis in terms of accumulating means to achieving knowledge. In other words, it's a

\footnotetext{
${ }^{2}$ These are all taken from Niiniluoto (2015).

${ }^{3}$ Park's solution is also extremely ad hoc, since only rationale for restricting the account in this way is that doing so is meant to avoid the aforementioned problem.

${ }^{4}$ As the parenthetical remarks here indicate, I am using 'abandon' and 'adopt' as placeholder terms for the propositional attitude that undergoes change in cognitive scientific progress. For Park and Bird, this attitude is belief (since belief is necessary for knowledge); for Dellsén, it is a form of acceptance (see subsection 3.1 for further discussion of this difference).

${ }^{5}$ Indeed, the episode would count as progressive according to Park's account even if the funding is merely a means to acquire a little bit of knowledge (less than what was previously lost), since that would still satisfy the second disjunct of Park's disjunctive account.
} 
mistake to move from the original to the extended epistemic account. Of course, the same would be true for noeticists - they shouldn't partly formulate their theory in terms of means to achieve understanding either. This does not mean that we will be forced to ignore important scientific contributions that did not themselves constitute (cognitive) scientific progress but were essential for bringing about scientific progress at some later date. Rather, such contributions can simply be classified as promoting (cognitive) scientific progress. Of course, epistemicists and noeticists will have different accounts of what counts as promoting progress in this sense - for epistemicists, something promotes progress when it facilitates or leads to increased knowledge; for noeticists, something promotes progress when it facilitates or leads to increased understanding. The epistemic and noetic accounts will then be evaluated with regard to whether they are correct in their verdicts about how different episodes (a) constitute scientific progress, (b) promote scientific progress, or (c) do neither. In what follows, I argue that the noetic account classifies cases into (a), (b) and (c) in a more plausible way than the epistemic account - Park's criticism notwithstanding.

\section{Responses to Park's objections}

I now turn to responding to Park's objections one by one.

\subsection{Is Belief Necessary for Understanding and Progress?}

Park starts by objecting to Dellsén's contention that belief is not required for scientific understanding (and thus for progress, on Dellsén's noetic account). On Dellsén's view, understanding involves not belief but a kind of acceptance for understanding-related purposes, where acceptance is understood in L.J. Cohen's (1992) sense as adopting or having a policy of treating something as true in a given context (Dellsén 2016: 76; see also 2017b, 2018). Now, Park's argument against Dellsén seems to be that if someone merely accepts, but does not believe, a proposition that's e.g. used in an explanation, "their peers might suspect that their ... understandings ... do not reflect the world" (Park 2017: 573). This is because, says Park, if the peers in question were to ask the person if she believed the theories on the basis of which she understands, she would have to admit that she merely accepts, but does not believe, those theories (Park 2017: 572-3).

This argument is not convincing. One important point about Cohen's (and, by extension, Dellsén's) belief/acceptance distinction is that it is not meant to correspond to how people use the terms 'belief' and 'acceptance' in ordinary language. Rather, it is meant to reflect a subtle difference in the attitudes we might take towards propositions. We might voluntary take them for granted in a specific context (acceptance), or simply involuntarily take them to be true regardless of context (belief). ${ }^{6}$ Thus when someone asks for our

\footnotetext{
${ }^{6}$ Of course, this is not the only possible way to define the terms 'belief' and 'acceptance' (see Schwitzgebel (2015) for a number of competing conceptions of the nature of belief). However, it is safe to say that belief is generally taken to be involuntary in an important way (see Williams (1973) and Alston (1988) for influential discussions); furthermore, belief is not generally taken to be context-sensitive in the way acceptance is on Cohen's definition (on this point, see Dellsén 2018: 13).
} 
opinions about something, e.g. with a question like 'What do you think about X?', the answer might reflect either our beliefs or our acceptances, depending on context. In a scientific context, i.e. when someone is asked for their opinion qua scientist (or, as van Fraassen (1980: 12) puts it, when the scientist is speaking ex cathedra), ${ }^{7}$ the answer would reflect what they accept rather than what they believe. Moreover, it is not as if one of these attitudes is the scientist's 'real' or 'considered' opinion about something, nor is it the case that only one of these attitudes is sensitive to evidence. Indeed, there are circumstances in which we cannot bring ourselves to believe a proposition that we nevertheless realize is supported by our evidence. In that case, we might accept the proposition - e.g., in a scientific context - even if we do not believe it. (For an example of this sort, see Dellsén's case of the deeply religious evolutionary biologist who cannot bring herself to believe the theory of natural selection, but nevertheless accepts it (Dellsén 2017a: 100-101).)

Given this, it should be clear that it is simply false that a scientist who is asked by her peers if she really believes something would need to say that she does not believe it. At most, what she would need to do is explain exactly what her attitude is towards the theory, but at no point should that lead her peers to conclude that her understandings do not reflect the world. If her peers are reasonable, they should let their judgment on this question be determined by their estimation of whether the scientist's attitude towards the theory (be it acceptance or belief) is based on sufficient evidence, sound methodology, and so forth. It is completely irrelevant for this kind of estimation whether the scientist's attitude is a voluntary context-dependent one (acceptance) or an involuntary context-independent one (belief). ${ }^{8}$

\subsection{Is Justification Necessary for Understanding and Progress?}

Park goes on to object to Dellsén's argument that epistemic justification is not necessary for scientific progress. ${ }^{9}$ Dellsén's point is that there are examples of scientific progress in which the relevant scientists were not (at the time) justified in believing the proposed theory to the extent required for knowledge. To illustrate his point, Dellsén uses a real historical example of Einstein's explanation of Brownian motion in terms of the kinetic theory of heat and the atomic theory of matter. In this case, both the explanans and the explanandum were

\footnotetext{
${ }^{7}$ It is worth noting that if Park's objection to Dellsén were correct, it would also serve as an objection to van Fraassen's constructive empiricism.

${ }^{8}$ Park also claims that "[w]hen scientists explain something in terms of a scientific theory, they believe that it [viz., the explanandum] is real" (Park 2017: 573). This appears to be an empirical claim about all scientists' mental states when engaging in a specific activity, viz. explanation. If so, it is almost certainly false given the existence of openly anti-realist scientists, such as Niels Bohr, who surely engaged in the practice of explaining various phenomena even though they did not believe that the relevant theories were true (see Folse (1985) and Faye (1991) for more on Bohr's views on the truth of his theories). It would be even less plausible to claim that this is some sort of conceptual truth, since it is clearly possible to explain with a theory you merely accept in Cohen and Dellsén's sense of the term (but do not also believe).

${ }^{9}$ Rowbottom (2010) also argues that justification is not necessary for scientific progress, but in a different way. Whereas Dellsén appeals to cases in which scientists arguably make progress in virtue of accurately explaining and/or predicting more than they previously could, Rowbottom (2010: 245-7) appeals to cases in which scientific theories become more theoretically virtuous in Kuhn's (1977) sense.
} 
unjustified (albeit correct), even by Einstein's own lights. Thus, argues Dellsén, Einstein cannot be said to have given us knowledge via his explanation, and so the episode cannot count as progressive by epistemicists's lights. Things looks very differently from the point of view of the noetic account, since Einstein clearly gave us understanding of Brownian motion. Park's response is not to dispute that the explanans and explanandum of Einstein's explanation were unjustified at the time, but to invoke his "means-end thesis" to argue that Einstein's contribution "served as a means to establish the existence of molecules in the subsequent research by Jean Perrin in 1908" (Park 2017: 574). Park gives a similar response to another example of Dellsén's in which an unjustified theory was used for understanding, viz. Wegener's proposal of his continental drift theory (Dellsén 2016: 80).

We have already seen what is wrong with this type of response. If the means-ends thesis is incorporated into an account of scientific progress itself, as per what I have called the extended epistemic account, then the account is unable to make crucial distinctions between cognitive and non-cognitive scientific progress - and indeed, seems to end up having to say that anything can count as scientific progress. To avoid this, epistemicists can instead say (as I have in effect suggested that they should) that the aforementioned episodes featuring Einstein and Wegener should be classified as cases in which scientific progress was promoted (rather than achieved). However, note that proponents of the noetic account need not make the same concession; rather, they can continue to maintain that Einstein and Wegener achieved scientific progress during these episodes. Since this is the judgment that Park himself seems to make about the two cases (Park 2017: 573-4), this has to count in favor of the noetic account as against the epistemic account. In sum, then, examples of this kind still favor the noetic account, as per Dellsén's original argument.

\subsection{Is Knowledge Sufficient for Understanding and Progress?}

Park's next two arguments against Dellsén concern whether knowledge is sufficient for understanding and scientific progress, respectively. Dellsén (2016: 76) briefly suggests that knowing individual propositions, e.g. the propositions that occur in an explanans and explanandum, would not suffice for understanding if one failed to grasp how to actually go about putting these propositions together in the relevant explanation. For example, one may know the height of a flagpole, the length of its shadow, the position of the sun, and the rectilinear propagation of light, and still not be able to explain or predict the length of the flagpole's shadow. Park's response is to grant that you would not have understanding in this case, but to insist that what is missing is simply more knowledge of a certain kind - viz., what he calls "inferential knowledge" (Park 2017: 575). In this case, the inferential knowledge in question consists in "know [ing] how the explanandum follows from the explanantia" (Park 2017: 575). So, Park argues, if you have all the knowledge relevant to an explanation of the flagpole's shadow - i.e., knowledge of the explanandum and explanantia, in addition to the relevant inferential knowledge - you will understand after all.

Dellsén could resist this argument by denying that what Park is calling "inferential knowledge" is knowledge of the same kind as that countenanced by the original epistemic 
account. After all, the kind of knowledge that Bird's epistemic account takes to be constitutive of scientific progress is propositional knowledge (knowledge of the propositions that constitute scientific theories), whereas Park's "inferential knowledge" appears to be a species of know-how. ${ }^{10}$ Of course, there are those who want to reduce know-how to propositional knowledge (e.g., Stanley and Williamson 2001), but the more traditional view is that know-how is a kind of ability, and thus by nature non-propositional. If so, Park's reply essentially trades on an ambiguity in the word 'know'. However, let me set that possible reply aside here, and simply grant Park the claim that this kind of "inferential knowledge" should count as knowledge in the same sense in which the epistemic account is using the term, i.e. as a species of propositional knowledge. What would be the upshots of that for the epistemic account of scientific progress?

Interestingly, Dellsén (2016: 77) already considered a related question when responding to a hypothetical objection to his argument. There, Dellsén used the term hypothetical explanatory knowledge to describe "knowledge of how a potential explanans would explain a potential explanandum if the explanans and explanandum are both true" (2016: 77). It should be clear that the differences between this and Park's "inferential knowledge", if any, are irrelevant to our current concerns. Now, Dellsén argued that the epistemic account cannot count increases in this kind of hypothetical explanatory knowledge as constituting genuine scientific progress, since it is "far more common than genuine scientific progress" (2016: 77). He illustrated the point with the example - a variation on one that was proposed by Bird himself as a clear case of non-progress - of a possible 'explanation' of why hot goat's blood would split diamonds according to a theory proposed by Nicole d'Oresme. Even if Oresme's theory was radically false and his proposed explanandum non-existent, Oresme could well have gained hypothetical explanatory knowledge (in Dellsén's sense) and inferential knowledge (in Park's sense). Since we surely do not want to say that Oresme achieved scientific progress in this case, an epistemicist cannot count hypothetical explanatory knowledge (i.e. inferential knowledge) as the kind of knowledge that the epistemic account takes to be constitutive of scientific progress. At the end of the day, then, Park's idea of including "inferential knowledge" as a knowledge of the relevant kind weakens rather than strengthens the epistemic account of scientific progress.

Park also argues against one of Dellsén's arguments that increases in knowledge are not sufficient for progress. Dellsén's argument (2016: 78) is that scientists could increase knowledge by gathering information about utterly spurious statistical correlations, such as that between childbirth rates and stork populations around a given city. By contrast, Dellsén contends that such an accumulation of knowledge would not amount to understanding, precisely because the correlations are spurious and thus incapable of supporting correct explanations or reliable predictions. For example, one could not explain increases in childbirth rates in terms of increased stork populations, or vice versa. According to Dellsén,

\footnotetext{
${ }^{10}$ Mizrahi (2013) argues that scientific progress often consists in increasing know-how, and argues for 'expanding' the notion of scientific knowledge to include both propositional knowledge and know-how in order to accommodate this point within a broadly-speaking epistemic account.
} 
this thus counts as a case that the epistemic account gets wrong and the noetic account gets right - a consideration against the former and in favor of the latter.

Park's objection to this argument is that "the same criticism can be leveled at the noetic approach" (2017: 576). To show this, Park considers an example of a research proposal that "outlines explanations of why one million individuals have the numbers of hairs on their heads that they have" (2017: 576). Park claims that this research "will yield understandings of why one million individuals have the numbers of hairs that they have, but will impress neither funding agencies nor scientific journals" (2017: 576). Park's case is a little underdescribed as it stands - it is not clear, for example, whether the research in question would use scientific methodology and whether the kind of explanations involved would naturally be classified as scientific explanations. But supposing that these questions are answered in the affirmative, it's hard to deny that the research could yield scientific understanding of why each of the million people have the number of hairs they in fact have. In that case, it would indeed have to be counted as constituting scientific progress by the lights of the noetic account. ${ }^{11}$

The first and most obvious response to this objection is that it would not, even if successful, establish parity between the noetic and epistemic accounts. After all, even if we accept everything Park says about the example, Dellsén's original childbirth/stork example would still count against the epistemic account and in favor of the noetic account. If successful, Park's number-of-hairs example counts against the noetic account, but of course it also counts just as forcefully against the epistemic account itself (since there is nothing in the example that prevents us from assuming that these explanations would yield knowledge). In effect, then, what Park has done is to try to save the epistemic account from Dellsén's original childbirth/stork example by pointing to a new case that (if successful) would undermine the noetic account and the epistemic account equally. Hence the noetic account would still come out on top, all things considered.

Moreover, it seems to me that proponents of the noetic account (and, indeed, proponents of the epistemic account) have the resources to treat Park's number-of-hairs example in a quite satisfactory manner - a treatment that is not available in Dellsén's childbirth/stork example. The idea would be that the number-of-hairs research would count as scientific progress, but as an instance of scientific progress on an issue or question that we find uninteresting, unilluminating, or otherwise insignificant. Not all instances of scientific progress are equal - some are simply more desirable than others. Put differently, we care more about making scientific progress on some issues than on others. Thus the reason why the number-of-hairs research would, as Park puts it, "impress neither funding agencies or scientific journals" (Park 2017: 576) is quite simply because they are not interested making progress into that issue. Notice that this type of response it not available in the childbirth/stork example, where it is not that the issue or question is uninteresting or

\footnotetext{
${ }^{11}$ That said, it might only count as very modest progress. Recall that progress is a matter of degree, and so the fact that such research would constitute some progress is compatible with the degree of progress being miniscule.
} 
unimportant (it is important to understand childbirth rates), but that the type of information or representation we would get about that issue is by its very nature lacking or deficient. ${ }^{12}$

\subsection{Idealizations and Simplicity}

Finally, I will briefly address Park's objections to two of Dellsén's "further advantages" of his noetic account. ${ }^{13}$

The first of these concerns idealizations that eliminate or exaggerate explanatorily irrelevant factors in order to emphasize core explanatory features - so-called 'minimalist idealizations' (Weisberg 2007: 642-645). Dellsén contends that these may increase understanding even when more accurate (i.e. less idealized) alternatives are available, but that this clearly does not amount to increasing knowledge. Park's objection is to appeal to his means-end thesis, arguing that discovering such idealizations would count as progressive on his extended epistemic account "given that they facilitate inferences about observables, and that those inferences are accompanied by an accumulation of observational knowledge" (Park 2017: 577). My response to Park's objection will be predictable at this point: I have argued that Park's means-end thesis is untenable as part of an account of scientific progress (see section 2), so even if the idealizations in question facilitate inferences about observables, we still would not have scientific progress in these cases on a plausible epistemic account. At most, these idealizations would promote scientific progress. However, Park himself seems to acknowledge that at least some of these idealizations should count as constituting scientific progress (Park 2017: 577).

The second of the two of Dellsén's "further advantages" that are discussed by Park concerns pragmatic virtues of scientific theories, i.e. virtues that do not make the theory more probable but instead make it easier to conceptualize or utilize the theory. In Dellsén's view, theoretical simplicity - i.e., the simplicity with which a theory is formulated (to be distinguished from ontological simplicity, defined in terms of the number of entities posited by the theory) - is a pragmatic virtue in this sense. Now, Dellsén contends that theoretical simplicity may contribute to understanding, and thus to scientific progress on the noetic view, in that it may be possible to explain or predict phenomena that cannot be explained or predicted with more complex theories. By contrast, theoretical simplicity cannot contribute to knowledge, since it is (assumed to be) a purely pragmatic virtue. Park (2017: 578) objects that, via his means-end thesis, theoretical simplicity may count as contributing to progress since it will be easier to derive observational consequences from the simpler theory than from the more complex one. Once again, my response is that Park's means-end thesis must be rejected for independent reasons. At most, Park can claim that replacing a more complex theory with a simpler one promotes (rather than constitutes) scientific progress. But, again,

\footnotetext{
${ }^{12}$ This idea could clearly be developed in more detail, e.g. by spelling out exactly what an issue or question is in this context and what makes it important, but I lack the space to do so here. Besides, since the response is essentially one that both noeticists and epistemicists should welcome, the issue is really quite independent of the adjudication of the noetic versus the epistemic view of progress that I am concerned with here.

${ }^{13}$ Dellsén briefly presents three such considerations at the very end of his paper (Dellsén 2016: 81-2). Park does not discuss the third advantage, having to do with the epistemic value of understanding and knowledge.
} 
this option seems not to be open to Park, since he explicitly asserts that choosing the simpler theory over the more complex one "constitutes scientific progress" (Park 2017: 578).

\section{Conclusion}

Park (2017) presents several objections to Dellsén's (2016) noetic account of scientific progress and to his arguments in favor of the noetic account as against Bird's $(2007,2015)$ epistemic account. I have argued that none of these objections succeeds. An important takehome message is that accounts of (cognitive) scientific progress cannot count just anything that promotes scientific progress as itself instances of progress. In particular, the epistemic account cannot simply be extended so as to count any means to knowledge as constituting progress in the relevant sense. Instead, we should simply distinguish between episodes that constitute and promote scientific progress, and evaluate account of scientific progress in terms of how they classify different episodes with respect to these categories. 


\section{References}

Alston, W.P. (1988). "The Deontological Conception of Epistemic Justification”, Philosophical Perspectives 2: 257-299.

Bird, A. (2007). "What is Scientific Progress?”, Noûs 41(1): 64-89.

Bird, A. (2008). "Scientific progress as accumulation of knowledge: A reply to Rowbottom", Studies in History and Philosophy of Science 39(2): 279-281.

Bird, A. (2015). "Scientific Progress", in P. Humphreys (ed.), Oxford Handbook in Philosophy of Science. Oxford: Oxford University Press.

Cohen, L.J. (1992). An Essay on Belief and Acceptance. Oxford: Clarendon Press.

Dellsén, F. (2016). "Scientific Progress: Knowledge versus Understanding", Studies in History and Philosophy of Science 56: 72-83.

Dellsén, F. (2017a). “Reconstructed Empiricism”, Acta Analytica 32: 95-113.

Dellsén, F. (2017b). “Understanding Without Justification or Belief”, Ratio 30: 239-254.

Dellsén, F. (2018). "Deductive Cogency, Acceptance, and Understanding", Synthese. DOI: 10.1007/s11229-017-1365-4.

Faye, J. (1991). Niels Bohr: His Heritage and Legacy. An Anti-Realist View of Quantum Mechanics. Dordrecht: Springer.

Folse, H. J. (1985). The Philosophy of Niels Bohr: The Framework of Complementarity. Amsterdam: North-Holland.

Kuhn, T.S. (1977). "Objectivity, Value Judgment, and Theory Choice", in The Essential Tension: Selected Studies in Scientific Tradition and Change. Chicago, IL: University of Chicago Press.

Mizrahi, M. (2013). "What is scientific progress? Lessons from scientific practice", Journal for General Philosophy of Science 44(2): 375-390.

Niiniluoto, I. (2015). "Scientific Progress", in E. N. Zalta (ed.), The Stanford Encyclopedia of Philosophy (Summer 2015 Edition).

Park, S. (2017). "Does Scientific Progress Consist in Increasing Knowledge or Understanding?", Journal for General Philosophy of Science. DOI: 10.1007/s10838-017-93632 .

Rowbottom, D. P. (2008). "N-rays and the semantic view of scientific progress", Studies in History and Philosophy of Science 39: 277-278.

Rowbottom, D. P. (2010). "What Scientific Progress is Not: Against Bird's Epistemic View", International Studies in Philosophy of Science 24: 241-255. 
Schwitzgebel, E. (2015). "Belief", in Edward N. Zalta (ed.), The Stanford Encyclopedia of Philosophy (Summer 2015 Edition). URL =

<https://plato.stanford.edu/archives/sum2015/entries/belief/>

Stanley, J., and T. Williamson (2001). "Knowing How", The Journal of Philosophy 98: 411-444. van Fraassen, B.C. (1980). The Scientific Image. Oxford: Clarendon Press.

Weisberg, M. (2007). "Three Kinds of Idealizations", Journal of Philosophy 104: 639-659.

Williams, B. (1973). "Deciding to believe", in Problems of the Self. Cambridge: Cambridge University Press, pp. 136-151. 